\title{
Haptic Perception Meets Interface Aesthetics: Cultural Representations of Touchscreen Technology in the Aftermath of the iPhone 2007
}

\author{
Katheryn Wright \\ Associate Professor, Core Division, Champlain College, USA \\ ORCID: orcid.org/oooo-ooo2-6485-9549.Email:kwright@champlain.edu
}

Received August 10, 2017; Revised September 12, 2017; Accepted September 15, 2017; Published September $20,2017$.

\begin{abstract}
The touchscreen is something other than a boundary between real and illusory worlds, or what Anne Friedberg (2009) calls a "virtual window" (p. 96). The aesthetics of that 'something else' is not determined by the technology itself, but by its use in a myriad of cultural practices including how it is represented as a commodity and an experience. This article examines the representation of touchscreen technology following the release of the iPhone in 2007, comparing a Nine Inch Nails rock concert and Blackberry commercial from 2008 with Bjork's album/app Biophilia and an American Express advertisement from 2011. Comparing these media experiences reveals a representational shift that occurs between the introduction of the touchscreen and the cultural integration of this technology just three years later. A focus on breaking through the frame of the screen shifts into screen interfaces as the building blocks for the virtual construction of "hybrid space" (De Souza e Silva, 2006).
\end{abstract}

Keywords: screen, touch, interface, haptic, body

\section{Introduction}

"Look, but don't touch." This common refrain asserts, again and again, that looking is safe and acceptable while touch, somehow, isn't. Eve Sedgwick (2002) suggests that sight is privileged over touch because "the sense of physical touch itself, at least so far, has been remarkably unsusceptible to being amplified by technology," so the visual gains an "authority" over the haptic (p. 15). In other words, the relative absence of technologies that mediate the sensation of touch have made it seem as if the visual is a more important way to understand the world around us. While there have been attempts to integrate haptic technology, they often take place at the periphery of media forms like the video game or movie theaters with their vibrating chairs. The popularization of touchscreen technology through the smartphone, however, has proven to be a game changer.

The above quote from Sedgwick's Touching Feeling: Affect, Pedagogy, Performativity was published in 2002, five years before the touchscreen interface became popularized through the release of the iPhone. Since then, popular culture has been a testing ground for figuring out the limitations and possibilities of this and similar devices. This article identifies a subtle but significant representational shift in regards to the aesthetics of the interface that takes place in the three years following the release of the first generation of Apple's iPhone in 2007. Comparing

(c) AesthetixMS 2016. This Open Access article is published under a Creative Commons Attribution Non-Commercial 4.0 International License (http://creativecommons.org/licenses/by-nc/4.o/), which permits non-commercial re-use, distribution, and reproduction in any medium, provided the original work is properly cited. For citation use the DOI. For commercial re-use, please contact editor@rupkatha.com. 
and contrasting a Nine Inch Nails rock concert and Blackberry commercial from 2008 with Bjork's Biophilia and an American Express advertisement from 2011 illustrates how an early fascination with physically breaking through the frame of the screen morphs into a promise of total immersion into a multiscreen environment. ${ }^{i}$ Musical artists like Trent Reznor and Bjork started to experiment with the touchscreen as an aesthetic medium at a time when its cultural significance was very much in flux and under negotiation.

\section{Haptic Themes in Media Studies}

The sense of touch plays a critical though historically overlooked and understudied role in media studies. Mark Paterson's The Senses of Touch: Haptics, Affects, and Technologies (2007) outlines the history of touch as it is mediated through different technologies in Europe. Paterson defines touch as a modality that results from sensory information traveling through receptors and nerves. Haptic refers to, more broadly, the sense of touch experienced by contact with external stimuli in combination with the somatic senses: proprioception, kinesthesia, and the vestibular sense (Paterson, 2007; Paterson, 2012). The haptic connects the external world felt through the skin with that felt sense of the body oriented within the outside world. Laura Marks examines the connection between physical touch and new media in Touch: Sensuous Theory and Multisensory Media (2002), forwarding the concept of "haptic visuality" to articulate the number of ways new media appeal to a multiplicity of senses and bodily affects (p. xiii). Haptic visuality takes into account the materiality of both the media object and the body of the spectator. Optic images ask viewers to enter into an illusory space while haptic images call attention to their material conditions, like Jackson Pollock's cigarette butts stuck into his drips of paint on the canvas which ask the spectator to think of the canvas in a much different way than the optical spaces of Jacques-Louis David's Oath of the Horatii (1784).

Theoretical discussions of screen technologies like film and television tend to prioritize the optic or visual experience, where the screen being looked at is more of a metaphor. The focus is on the illusory space while the materiality of the screen is meant to be forgotten as audiences fall into the narrative world projected on it. Scholars who have paid attention to the materiality of the screen include Lev Manovich and Anne Friedberg. Manovich constructs the history of the screen in The Language of New Media (2002), explaining that the computer screen is both a window to illusory space and a "virtual instrument panel" with an emphasis on its surface (p. 96). Friedberg in The Virtual Window (2009) traces the cultural history of what she calls the "virtual window" to Renaissance painting, where Leon Battista Alberti's 15th century architectural treatise "On Painting" initiates the spatial relationship of modern spectatorship that situates the viewer or audience in front of a framed surface (pp. 5-12). Both of these trajectories focus on the framing function of the screen that separates the body from the representational plane of the screen. Margaret Morse in "Body and Screen" (1999) offers another reading of the material significance of the screen. She writes, "The screen...now marks a cybernetic frontier between the physical and the conceptual, the body and the machine, bio-technology and communications" (p. 64). Instead of separating the body and representational space, the screen is a contact point between them. ${ }^{\text {ii }}$

The haptic visuality of new media objects extends the conversation about contemporary aesthetics beyond the visual into the material body, but doesn't really take on the screen itself as an object of analysis like Manovich, Friedberg, and Morse do. Still, Marks' focus on materiality offers a useful starting-point to consider haptic technologies like the smartphone. Drawing on Gilles Deleuze and Felix Guattari's differentiation between smooth and striated space in $A$ Thousand Plateaus: Capitalism and Schizophrenia (1987), Marks explains how haptic perception 
allows one to navigate through smooth spaces of immediate, local environments while optical perception is more abstracted, more distanced (p. xii). Think about the difference between feeling, looking, and walking around a forest and looking at a map to figure out how to get out of the woods. Feeling, looking, and walking requires engaging with the "layers" of the forest in relation to one's body, unlike the charted path of a map that abstracts the haptic experience into a visual grid on paper (p. xi). Haptic perception is the sensation of touch through the physical contact with the skin or other sensory organs, so what happens when the screen interface becomes the environment that is being explored instead of a forest? The screen is a material surface that tends to be forgotten when the focus is what's on it, but the touchscreen asks its users to approach screens differently. The screen is smoothed out where it can be touched rather than function primarily as a frame through which spectators optically examined the striated space of classical Hollywood cinema.

In 2007, Apple introduced the touchscreen interface for their new model of iPhone. The iPhone popularized a form of multi-touch technology, where the device recognizes two or more points of contact with the screen. There are two types of touchscreens, resistive and capacitive, and multi-touch technology comes from the latter. With capacitive touchscreens, an insulator (like glass) is coated with a transparent conductor and contact with the surface disrupts the electrostatic field (Mathema, 2015). Building on capacitive technology, multi-touch interfaces allow users to make contact with multiple points on the screen to perform different functions like pinching. Pioneered by a research group at the University of Toronto in 1982, a company called Fingerworks continued to develop multi-touch technology throughout the 199os until Apple acquired them in 2005 (Prince, 2010). The release of the iPhone in 2007 brought multi-touch technology to a mass market.

\section{One Year Out: The Power of Touch}

The introduction of multi-touch technology marks a critical moment in the history of haptic technologies, which coincides with a change in how touchscreen technologies were represented in popular culture after 2007. In 2008, a year after the introduction of the iPhone to the American public, Nine Inch Nails' Lights in the Sky tour featured a stage-sized touchscreen that lead-singer Trent Reznor interacted with throughout the second and third acts of each concert. ${ }^{\text {iii }}$ Audience members at this specific show and other concerts during the tour recorded the event and posted it on YouTube. The tour was supposed to be made into a 3D movie by James Cameron, but plans fell through and the raw footage was released to fans who compiled their own documentary called Another Version of the Truth: The Gift, according to the NinWiki. Independently financed in part by Trent Reznor, the concert featured a series of stage-sized screens that were lowered and raised. The preproduction work and interface design for Lights in the Sky began during NIN's Live: With Teeth tour where Reznor used one large scale, semi-transparent screen in order to display video footage reinforcing themes for specific songs. According to Reznor, the use of three screens in Lights in the Sky was an extension of the Live: With Teeth design concept (Gardiner, 2008). The show, designed by Reznor and Rob Sheridan, his artistic director and realized in part by lighting designer Roy Bennett and the tech company Moment Factory, combines laser technologies, particle-based animation that run off several Linux-based devices simultaneously (the visual display is live and interactive), choreographed staged lighting, and three primary screens, a highresolution Barco $\mathrm{D}_{7}$ screen and the two semitransparent "stealth" screens which are reflective elements linked together like a chain so they can be transparent or opaque depending on how 
they are lit (Gardiner, 2008, par. 11 - 12). Along its background ran a series of lasers that detected Reznor's position as he moved towards and away from the stealth screen.

During the performance of the track entitled "Only" from the album With Teeth, onscreen animations generated in real-time visually track Reznor's movement across the stage. Essentially, Reznor uses the downstage stealth screen as a giant multi-touch interface. This particular touchscreen works via a series of lasers running along the back of the downstage screen. The onscreen animations generated in real-time focuses the viewer towards Reznor's physical interaction with the stealth screen. As Reznor moves across the stage, the opening follows him. He steps back, and the opening closes and the field is reconstituted. The particle animations on display intersect with, and depend on, Reznor's physical interaction with the material interface. It is here where Reznor begins the process of crossing through the frame of the screen. Although he never quite touches it, the animations create the illusion of breaking through the screen's surface. The touchscreen offers a way to cross the frame that separates the spatial reality of the viewer from the virtual space of representation, linking the physical and digital through his body. Still, Reznor remains trapped behind the screen in order for that illusion to work. To cross the frame of the screen is transgressive within the field of modern aesthetics, much like breaking through the imaginary fourth wall of the stage, but the interplay between screen and body during the concert translates into an optical effect for everyone watching. Like a painting or film, this performance can only be accessed through a proscenium, a frame, which separates the spectacle from those watching it.

The imagery with Reznor's body pushing through an opening in the digital display also adds a sensuality to the performance. Reznor's movement into and away from the screen seems almost like he's caressing it, revealing and concealing his presence from the audience in a kind of virtual striptease. This suggestive gesture during the concert parallels the music video for the same track, directed by David Fincher, where Reznor's face appears in a pin screen. The pressure of the pins against your skin as they respond to the movement of the body creates an image on the other side of the toy, visible through a flat plane of plastic. A touchscreen replaces the pin screen, while Reznor's body replaces the computer-generated animation scheme. The sense of touch registers as a visual texture captured within the frame of a simple plastic (in the case of the video) or cutting edge stealth screen.

A commercial for the Blackberry Storm smartphone released in November 2008 focuses on the symbolic act of crossing through its frame. Not only does this commercial demonstrate the myriad of possibilities that await when you buy a Blackberry Storm, it explores the hidden potential of haptic technologies in a wireless world. The advertisement begins when a woman touches a semi-translucent rectangular field signifying the new touchscreen interface on the Blackberry, a young boy flying a kite within the frame of the smartphone's video recording interface unfolds into $3 \mathrm{D}$. Image planes begin to layer behind her, and she touches the screen again. A rock concert unfolds from a recording to real life as logos of social networking sites fall into frame with tennis players hitting over a calendar. The third touch reveals business applications, a movie theater and photographs. These layers merge back together to form the casing of the Blackberry Storm with an image of the woman shown through the interface with a male voice-over asking the audience to "touch and connect, to everything you love in life."

Paterson asserts, "With tactility we are not affected or altered by the sense-object itself, nor simply through the medium (flesh), but [are] actually in synchrony with the medium" (p. 17, italics in original). A haptic interface removes a layer of technology like keyboards and controllers that mediate the relationship between sender and receiver, leaving only the touchscreen. During 
the concert and in the commercial, the touchscreen offers a more instantaneous connection with others simply because physical touch seems more immediate. Any attempt to capture the immediacy of the real world must, in turn, recognize the material reality of the processes of mediation (Bolter and Grusin, 2010, pp. 20-50). Both Reznor and the woman are situated behind the plane of the screen, while the power of touch alongside the relative positions of their bodies allow them to metaphorically enter into striated space. The touchscreen becomes the bridge between reality and representation, or the physical and the digital.

\section{Three Years Later: Screen Liberation}

Released in 2011, the American Express Membership Rewards Points "Social Currency" campaign demonstrates a change in popular representations of touch and technology. Like Reznor's performance, this television advertisement begins onstage and like the Blackberry commercial, a woman stands in front of a holographic interface. Rather than the performer reaching out to touch a screen, the camera pans around to the perspective of the audience. Another rectangular frame is multiplied in the audience, when the scene shifts to a woman scrolling through her touchscreen smartphone outside a closed store. Presumably, images of the apps she is using to "shop anywhere" are projected onto the windows behind her. The camera quickly cuts to someone instant messaging on a laptop in a bedroom that shifts to a projection of the conversation onto skyline. The narrative returns to the shopper virtually trying on clothes by interfacing with the hologram, and again to the concert. The frame in the audience becomes a video streaming player, and several semi-transparent windows in front of the band represent possible perspectives any user with a smartphone could use to record the event.

The multiscreen environment of the American Express commercial represents one version of what Adriana de Souza e Silva (2006) calls a "hybrid space" (connected, mobile, social) that has liberated the frame from the screen and, in the case of the projections on the storefront and cityscape, bypassed the frame of the screen altogether (p. 261). The author explains, "From the merging of mixed reality and augmented spaces, mobility, and sociability arises a hybrid reality...a hybrid space is not constructed by technology. It is built by the connection of mobility and communication and materialized by social networks developed simultaneously in physical and digital spaces" (pp. 265 - 266). De Souza e Silva (2006) describes what could also be called augmented space, mixed reality, computer-mediated reality, or even more simply, multimedia environments. All of these concepts speak to the intersection of physical and digital spaces that, up until this point, the screen has metaphorically divided.

Biophilia, an album by Bjork and Jonas Sen, is another example of hybrid space in popular culture. It's not only a music album, but a dynamic sequence of onscreen animations by Nikki Dbben and an application suite for the Apple iPad designed by interactive artist Scott Snibe. Promotional stills advertising the album depict animations from the app around Bjork, similar to the multiple interfaces in the American express commercial. Through the app, a user can leverage the haptic interface of the iPad to invent new ways to explore intersections between nature, music, and technology. They are able to make their own melody determined by the phase of the moon, in the case of the track entitled "Moon." Rather than a credit card, the touchscreen itself provides a way into this sandbox of musical exploration. Bjork's music video for "Moon" mirrors the interface of the app, integrating its visual architecture into the onscreen spectacle. Rather than confronting the screen like Reznor, Bjork is surrounded by and surrounds the interface with her body at its center. The universe of the app circles her body, as she becomes the surrogate for 
the user who (if they were in Bjork's position) reaches out to touch one of the constellations. The truncated beat of the melody of the song echoes the moon's cyclical phases as they function on the app itself. There is a sensuality of being surrounded by animations similar to the Nine Inch Nails stealth screen performance, but Bjork uses the interface to compose her music instead of just entering into it.

Haptic perception becomes the means through which the layers of sounds and images of "Moon" begin to make sense; the gestures of a user working with the app mirrors what Bjork uses to create her version of the song in the music video. Touch is the primary way to explore the interactive elements of the experience, making tactility central to the creative potential of haptic perception enabled in this hybrid space. By touching the screen, a user does something other than cross its frame. They are able to create within the hybrid space that Bjork, Sen, Dbben, and Snibe designed. No longer a spectator, the user participates in and through the interface. The album isn't about crossing through the frame of the screen, but navigating through it.

This second commercial and Bjork's album/app illustrates a hypermediated immediacy without any implied paradox; the critical distance between real and virtual in the first two examples no longer exists (Bolter and Grusin, 2000, p. 3). Here, the integration between digital and physical is a given. The frontal orientation of the first two examples give way to an in the round experience of the interface. There is no frame to be crossed, but a media ecology within which to navigate. The right device or credit card allows you to live in it more effectively. As De Souza e Silva (2006) notes, "users do not perceive physical and digital spaces as separate entities and do not have the feeling of 'entering' the Internet, or being immersed in digital spaces, as was generally the case when one needed to sit down in front of a computer screen and dial a connection" (p. 263). Rather than unleash the "magic" of the virtual world, a body -- like the woman touching her screen in the rain -- provides access to a hybrid space that already exists as the real world.

\section{A Representational Shift}

A representational shift occurs within the relatively short time span between the first set of examples developed during 2008 and those from 2011. While the live performance of "Only" and the Blackberry commercial represent a cultural fascination of crossing the frame of the screen by physically touching it, the American Express advertisement and Biophilia take for granted that the touchscreen is part of a mobilized, virtual hybrid space that can be touched and felt as much as it can be seen and heard. The body becomes the primary access point or medium through which this integration of the physical and digital can be haptically perceived. It's important, however, not to ignore the materiality of the screen within the virtual hybrid space hypothesized by the touchscreen fantasies of Bjork and American Express. To do so would be to position an interface aesthetics without an interface, which works to erase the cultural contexts that underpin its construction. Touchscreen technologies are as much haptic as they are optic, approaching the screen as something other than a window or frame and as something more than a surface or instrument panel. It is felt as texture before it is seen as a text. It is immediate and material. It is affective. In order to engage more fully in haptic media studies (see Paterson et. al, 2017), scholars need to continue to contextualize the textural expression of hybrid space in addition to its visual effects in order to articulate the role tactility plays in the embodied experience of technology. 


\section{Notes}

${ }^{\mathrm{i}}$ Earlier versions of this paper were presented at the Society of Cinema and Media Studies Annual Conference and the Popular Cultural Association National Conference, both in 2012.

ii An extended overview of these theories of the screen can be read in the first chapter of Into the Screenscape: Screens, Bodies, and the Biopolitics of the Population (2010).

iii The author attended this concert in person on October 29, 2008 in Jacksonville, FL. Part of this analysis is based on that performance. A phenomenological reading of the entire event can be found in Into the Screenscape: Screens, Bodies, and the Biopolitics of the Population (2010) and, in a modified form, the article "Reaching for the Screen in Nine Inch Nails' Lights in the Sky" (2012) published by Refractory.

\section{References}

Allan Moulder. (n.d.). Nine Inch Nails Lights In The Sky Tour 2008. Retrieved from https://www.youtube.com/watch?v=Bmxt7ORGFVo

Apple Reinvents the Phone with iPhone. (n.d.). Retrieved from https://www.apple.com/newsroom/2007/o1/ogApple-Reinvents-the-Phone-with-iPhone/

Björk: Biophilia on the App Store. (n.d.). Retrieved from https://itunes.apple.com/us/app/bj\%C3\%B6rkbiophilia/id $434122935 ? \mathrm{mt}=8$

Bolter, J. D., \& Grusin, R. (200o). Remediation: Understanding New Media (Revised ed. edition). Cambridge, Mass.: The MIT Press.

David, J. (1784). The Oath of the Horatii. Retrieved from http://www.louvre.fr/en/oeuvre-notices/oathhoratii

de Souza e Silva, A. (2006). From Cyber to Hybrid: Mobile Technologies as Interfaces of Hybrid Spaces. Space and Culture, 9(3), 261-278.

Deleuze, G., \& Guattari, F. (1987). A Thousand Plateaus: Capitalism and Schizophrenia. (B. Massumi, Trans.) (2 edition). Minneapolis: University of Minnesota Press.

Friedberg, A. (2009). The Virtual Window: From Alberti to Microsoft. Cambridge, Mass.: The MIT Press.

Gardiner, B. (2008, September 12). NIN Dazzles With Lasers, LEDs and Stealth Screens. Wired. Retrieved from https://www.wired.com/2008/og/nin-dazzles-with-lasers-leds-and-stealth-screens/

Jackson Pollock. Full Fathom Five. 1947 | MoMA. (n.d.). Retrieved from https://www.moma.org/collection/works/79070

Lights In The Sky Tour - NinWiki. (n.d.). Retrieved August 9, 2017, from http://www.nin.wiki/Lights_In_The_Sky_Tour

Manovich, L. (2002). The Language of New Media (Revised ed. edition). Cambridge, Mass.: The MIT Press.

Marks, L. U. (2002). Touch: Sensuous Theory And Multisensory Media (1 edition). Minneapolis: Univ Of Minnesota Press.

Mathema, C. (2015, April 17). What's the Difference Between Resistive and Capacitive Touchscreens? Retrieved from http://www.electronicdesign.com/displays/what-s-difference-between-resistive-andcapacitive-touchscreens

McLean, P. (2010, January 23). Inside the multitouch FingerWorks tech in Apple's tablet. Retrieved from //appleinsider.com/articles/10/o1/23/inside_the_multitouch_fingerworks_tech_in_apples_tablet 
Mike McDonnell. (n.d.). AMEX Social Currency Commercial. Retrieved from https://www.youtube.com/watch?v=BXFxx-J9RDQ

Morse, M. (1999). Body and Screen. Wide Angle, 21(1), 63-75. https://doi.org/10.1353/wan.1999.0007

Neo Shinesnh Channel. (n.d.). Björk - Biophilia (FULL ALBUM). Retrieved from https://www.youtube.com/watch?v=R7MTU_VVsnA

NineInchNailsVEVO. (n.d.). Nine Inch Nails - Only. Retrieved from https://www.youtube.com/watch?v=mDsqpeiTqg8

Paterson, M. (2007). The Senses of Touch: Haptics, Affects and Technologies. Oxford ; New York: Bloomsbury Academic.

Paterson, M. (2012). Movement for Movement's Sake? On the Relationship Between Kinaesthesia and Aesthetics. Essays in Philosophy, 13(2), 471-497.

Paterson, M., Parisi, D., \& Archer, J. E. (2017). Haptic Media Studies. New Media and Society, 1-10.

PotBellyWarrier. (n.d.). BlackBerry commercial. Retrieved from https://www.youtube.com/watch?v=8iQ9oepKScE

Sedgwick, E. K. (n.d.). Touching Feeling (Series Q) Publisher: Duke University Press Books.

Wright, K. (2010). Into the Screenscape: Screens, Bodies, and the Biopolitics of the Population (Dissertation). Florida State University. Retrieved from http://fsu.digital.flvc.org/islandora/object/fsu\%33253305/

-- . (2012). Reaching for the Screen in Nine Inch Nails' Lights in the Sky. Refractory, 21. Retrieved from http://refractory.unimelb.edu.au/2012/12/28/wright/ 